\title{
Surgical Removal of Numerous Foreign Bodies from the Foot Caused by Sea Urchin Spines
}

\author{
Mahmoud A. Hafez ${ }^{*}$, Ahmed Mounir Al-Dars
}

The Orthopaedic Department, October 6 University, Cairo, Egypt.

Email: *mhafez@msn.com,

Received June 29 $9^{\text {th }}$, 2012; revised July 31 ${ }^{\text {st }}$ 2012; accepted August $30^{\text {th }}, 2012$

\begin{abstract}
Injury from sea urchin spines is not rare, especially during summer holidays in the sea side. Failure to remove these spines or inability to remove them completely can lead to long-term squeal of pain and impaired function. Treatment methods include alternative medicine, LASER and surgery. We describe the surgical removal of 102 sea urchin spines from the foot of a 36-year-old man. The wounds healed completely. Although, he initially complained of a mild discomfort on weight bearing, the symptoms disappeared 2 weeks later.
\end{abstract}

Keywords: Sea-Urchin; Foreign Body; Surgical Technique; Infection; Foot

\section{Introduction}

Sea urchins belong to the phylum Echinodermata, class Echinoidea. They inhabit oceans and they do not exist in fresh water. Their spines are made of $\mathrm{CaCO}_{3}$ crystals that make them radio-opaque, however the radio-opacity may vanish if the calcium is absorbed by the host tissues. Therefore, early detection will allow radiological visualization. The spines can cause local irritation, infection, foreign body granulomas, chronic synovitis and arthritis, with long term morbidity [1].

Injury from sea urchin spines is not rare, especially during summer holidays in the sea side. Failure to remove these spines or inability to remove them completely can lead to long-term sequelae of pain and impaired function. Treatment methods include alternative medicine, LASER and surgery. We describe the surgical removal of 102 sea urchin spines from the foot of a 36year-old man.

\section{Patients and Methods}

A 36-year-old man stepped on a sea urchin during his holidays in the Mediterranean Sea. A first attempt of removal of the spines by a local doctor was fruitless. He presented to the orthopaedic department in our hospital five days after the injury. His right heel showed numerous small foreign bodies (Figure 1), some of them were prominent and others appeared as black spots. There was an evidence of local infection in two small areas, two centimetres in diameter each, which were associated with

*Corresponding author. blisters. On further enquiry, these foreign bodies were noted to be sea urchin spines. We opted for surgical treatment.

Surgery was done under general anaesthesia with the patient positioned in prone under tourniquet control. A hand surgical instrument set was used, including; fine curved forceps, non-toothed forceps, skin-hook, and a size 15 blade (Figure 2). Extra caution was needed while holding and extracting the spines because they are thin and fragile. The fine curved forceps were used to push the skin deeper, around the spine, in order to make the spine more prominent. A skin-hook was also used to withdraw the spine. Then, the extraction was completed

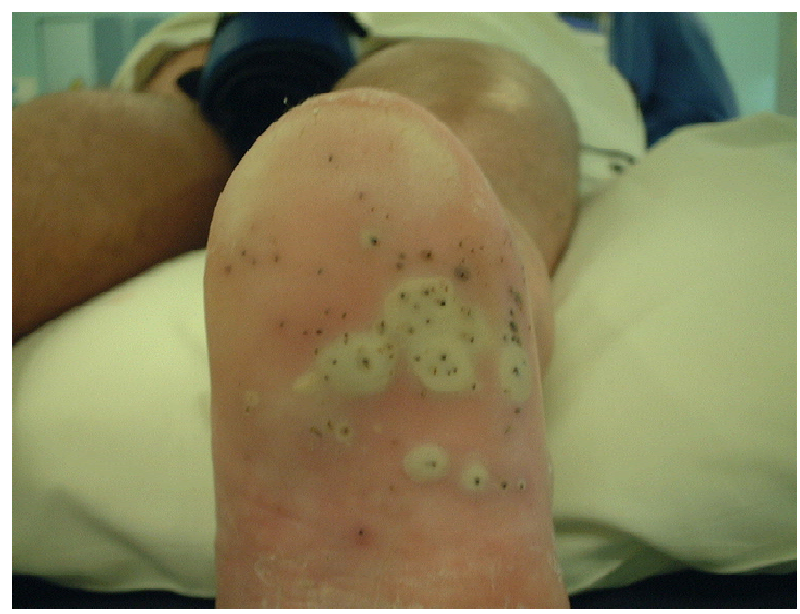

Figure 1. Right heal showing numerous See-Urchin spines. The heal shows small foreign bodies, some of them were prominent and others appeared as black spots. 


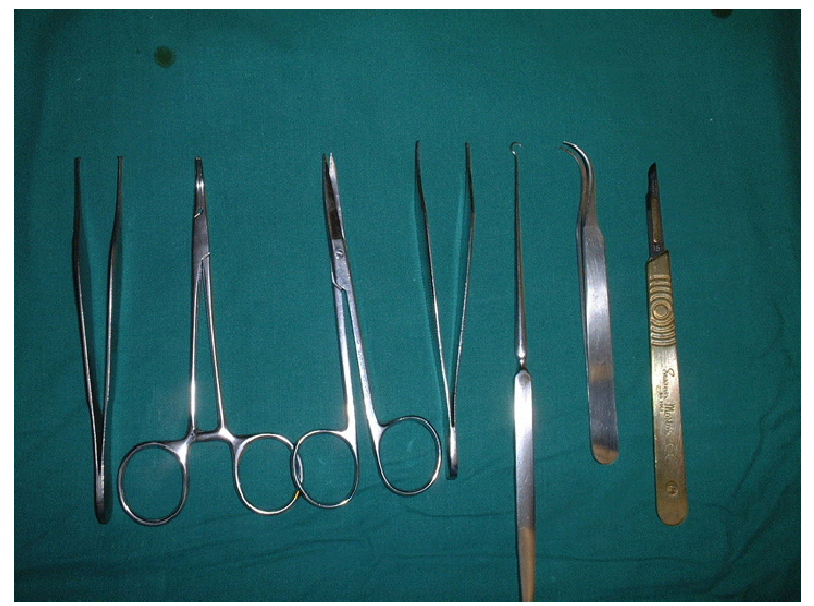

Figure 2. Hand surgical instruments set. Instruments set including: fine curved forceps, non-toothed forceps, skinhook, and a size 15 blade.

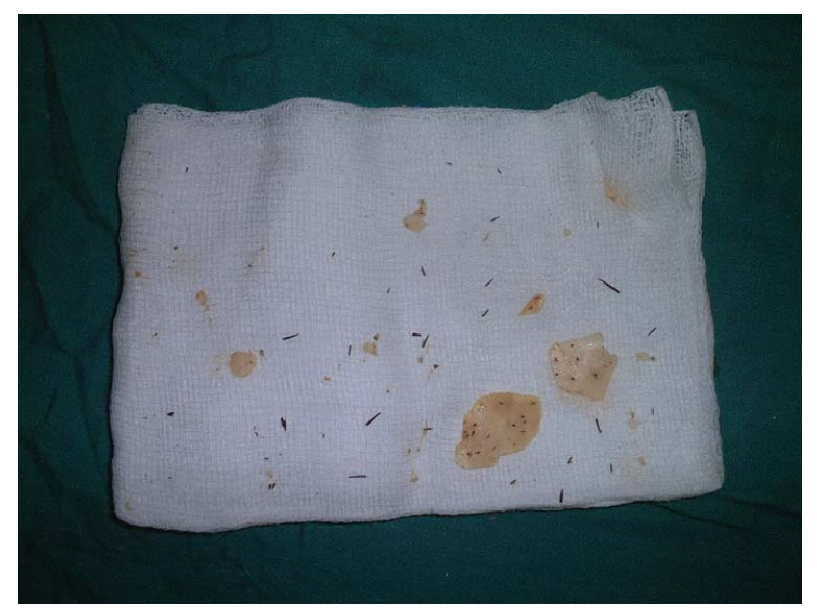

Figure 3. Removed foreign bodies. The foreign bodies were counted as 102 including separated spines and buried spines.

by gently using the either forceps. For the completely buried spines, a small incision $(0.5 \mathrm{~cm})$ was made over the black spot and then, a skin hook was used to withdraw the spine as described above. The removal was easier in the infected areas. It seemed that the blistering resulted in partial withdrawal of the spines from the deep tissues. Complete excision of these blisters resulted in easy removal of 60 spines. The time of surgery was 75 minutes.

\section{Result}

All foreign bodies were removed and we counted 102 spines (Figure 3). The patient had no postoperative complications and he was discharged home the day after. The wounds healed completely although he initially complained of a mild discomfort on weight bearing, which disappeared at the last follow up, two weeks later.
The patient did not turn up in the later follow up appointments.

\section{Discussion}

Sea urchin spines can cause local irritation, infection, foreign body granulomas. When they penetrate the dermis (or sub cutis). Newmeyer [2] reported that infection could be due to the effect of their toxins, epithelial covering and any contamination from the water in which the injury occurred. Removal of sea urchin spines is not easy as the spines are small and they can easily break. Several cases have been reported, describing different techniques for removal. Falkenberg [3] reported a technique using alternative medicine by crushing the spines in situ by stone then voiding fresh urine on the wound. Burnett [4] reported the use of bolus ejection and Boer et al. [5] reported the use of erbium: YAG LASER. Newmeyer [2] reported surgical removal of see urchin spines from the hand.

The surgical technique we used is simple, aseptic, and efficient and does not need sophisticated equipments. The results were excellent and the spines could be removed entirely even without radiological localisation.

Injury from sea urchin spines can cause pain and disability if left untreated. Awareness of the nature of this injury and modalities of treatment is important to emergency physicians and surgeons. Surgical removal is recommended especially when there is infection. Surgery should be done under general anaesthesia, in theatre. The surgeon should be prepared for a long and tedious task. Fine instruments, good theatre light, tourniquet and surgical loupe are invaluable.

\section{REFERENCES}

[1] W. J. Dahl, P. Jebson and D. S. Louis, "Sea Urchin Injuries to the Hand: A Case Report and Review of the Literature," Iowa Orthopaedic Journal, Vol. 30, 2010, pp. 153-156.

[2] W. L. Newmeyer 3rd., "Management of Sea Urchin Spines in the Hand," Journal of Hand Surgery-American Volume, Vol. 13, No. 3, 1988, pp. 455-457. doi:10.1016/S0363-5023(88)80031-5

[3] P. Falkenberg, "Sea Urchin Spines as Foreign BodiesAn Alternative Treatment,” Injury, Vol. 16, No. 6, 1985, pp. 419-420. doi:10.1016/0020-1383(85)90062-2

[4] J. W. Burnett, "Bolus Ejection: A Method for Removing sea Urchin Spines,” Annals of Emergency Medicine, Vol. 39, No. 1, 2002, pp. 94-95. doi:10.1067/mem.2002.120747

[5] A. Boer, F. R. Ochsendorf, C. Beier and R. Kaufmann, "Effective Removal of Sea-Urchin Spines by Erbium: YAG Laser Ablation,” British Journal of Dermatology, Vol. 145, No. 1, 2001, pp. 114-116. doi:10.1046/j.1365-2133.2001.04306.x 